\title{
Identification of Prior Factors Influencing the Mode Choice of Short Distance Travel
}

\author{
Ming Li, ${ }^{1}$ Guohua Song, ${ }^{1}$ Ying Cheng, ${ }^{2}$ and Lei $\mathrm{Yu}^{1,3}$ \\ ${ }^{1}$ MOE Key Laboratory for Urban Transportation Complex Systems Theory and Technology, Beijing Jiaotong University, \\ Beijing 100044, China \\ ${ }^{2}$ Beijing Transport Energy \& Environment Center, Beijing 100073, China \\ ${ }^{3}$ College of Science and Technology, Texas Southern University, 3100 Cleburne Avenue, Houston, TX 77004, USA
}

Correspondence should be addressed to Ming Li; limzlxs@gmail.com

Received 12 October 2014; Revised 9 January 2015; Accepted 20 January 2015

Academic Editor: B. S. Daya Sagar

Copyright (C) 2015 Ming Li et al. This is an open access article distributed under the Creative Commons Attribution License, which permits unrestricted use, distribution, and reproduction in any medium, provided the original work is properly cited.

\begin{abstract}
Short distance trips are defined as any trips shorter than or equal to 5 kilometers, which have been found to be a big contributor to the traffic congestion problem. This paper is intended to analyze factors that influence the mode choice of short distance travels in order to help reduce short distance trips by cars. A survey is conducted at two typical kinds of residential areas, one with a high proportion of short distance car trips and another one with a low proportion. Then, by applying the structural equation modeling, it is found that the age, the household income, and the vehicle ownerships have a significant effect on the mode choice of short distance travels. Besides, among residents of the same type (same age, household income, and vehicle ownerships) in surveyed areas, those in the area with a better green-mode travel environment account for a higher proportion choosing the green mode than those in other areas. Based on this result, it is concluded that a better green-mode travel environment leads to a higher proportion of green-mode travels. In the end, the paper shows residents' stated willingness to change travel modes from cars to the green mode.
\end{abstract}

\section{Introduction}

An explosive increase of the car ownership has worsened traffic congestion and air pollution problems in Beijing. According to the statistics in 2010, there were 41.3 million trips per year in Beijing [1], in which the car trips accounted for $33 \%$. The short distance car trips, defined as any trips shorter than or equal to 5 kilometers, reached as high as over $40 \%$ of all car trips, which is more than twice of that in Copenhagen and is becoming a big contributor to the traffic congestion problem [2]. From the statistic result, it can be observed that short distance car trips can be attributed to three main purposes, among which commuting trips rank the highest, followed by purposes of picking-up or droppingoff students and shopping. Proportions of trips for these three purposes are $45.1 \%, 21.2 \%$, and $9.8 \%$, respectively, which account for as high as $76.1 \%$ of the total short distance car trips [3]. In order to improve traffic conditions and mitigate traffic congestions, the government has implemented many travel demand management (TDM) policies, such as the restrictive measure on the vehicle use, vehicle registration via a lottery system, and raising fees for parking in the center district. However, the effectiveness of those measures has not been encouraging, especially in view of the continued excessive use of cars for short distance travels.

Traffic system is a dynamic complicated one which consists of travelers, travel modes, and roads. Travelers play an important role in the system. Nowadays, mode choice in the short distance trip is a hot issue in the traffic research, which is often considered as a discrete problem. With Beijing as the study area, the primary objective of this paper is to identify reasons why so many short distance car trips exist. After a summary of existing studies, this paper designed a three-step approach. First, the paper analyzed both the data provided by the Fourth Comprehensive Traffic Survey in Beijing [2] and the data collected from field surveys at two kinds of residential areas. Second, based on a structural equation model, factors influencing the mode choice of the short distance travel were identified. Finally, with the stated preference (SP) survey, the stated willingness of mode shift 
and preconditions were analyzed. Findings from this paper can help the government develop effective TDM policies that promote the mode shift from cars to a green mode (i.e., bus, subway, bike, and walking in this paper) and contribute to optimizing the travel mode structure and mitigating traffic congestions.

\section{Overview of Existing Studies}

In the past years, many studies have been conducted that focused on medium and long distance travels, including ones by Algers [4], Mallett [5, 6], and Limtanakool et al. [7, 8]. However, recent studies have indicated that many residents prefer car trips to other modes, even though for a very short distance trip. In Great Britain, Mackett [9] concluded that only $22 \%$ of short distance car trips were essential, and the rest could shift to other modes. In order to attract motorists out of their cars onto alternatives for short trips, many cities have been adjusting the travel mode structure by limiting vehicles and improving public transit. Mackett [10] identified that the most significant action to reduce the number of car trips is to improve public transit. de Nazelle et al. [11] suggested that reducing short distance car trips would modestly reduce the air pollution from the mobile source. Maibach et al. [12] reviewed a number of immediate, practical opportunities to implement policies and programs. In conclusion, reducing short distance car trips is necessary and meaningful for traffic and environment.

Recently, more and more studies have focused on looking for reasons why people use their cars for short distance travels. By investigating car trips and alternative travel modes, Mackett [9] showed some main reasons for short distance travels, such as carrying heavy goods, shortage of time, and convenience. After analyzing short distance trips and an attitude survey, which was carried out in Gothenburg, Forward [13] concluded that attitudes, subjective norm, perceived behavioral control, and habit can be considered as main influencing factors. Wu and $\mathrm{Li}$ [14] made an exploratory research to conclude that external environment, public service, cost restriction, and induction factors are four most important factors that affect urban residents' mode choices of short distance travels. Kuby et al. [15], Limtanakool et al. [7], and Loo et al. [16] concluded that the land use had an important effect on the mode choice. Walton and Sunseri [17] examined ten main factors on short distance trips, including weather and parking charges. Kim and Ulfarsson [18] thought an environment that attracts people's interest and provides activity opportunities encourages people to walk on short distance trips. There were some other related studies that focused on the design of residential area [19-21].

Models on the travel mode choice include the aggregate model and disaggregate model. Ben-Akiva et al. [22] developed a dynamic model that focused on the traffic congestion during peak hours. In the model, a limited number of bottlenecks were considered. From then on, the disaggregate model became more and more popular, such as multinomial logit (MNL) model [23] and nest logit (NL) model [24, 25]. By considering the problem of independence of irrelevant alternative (IIA) in the logit model [26], Bhat [27] developed a new heteroscedastic extreme value model for the intercity mode choice. Besides, since 1980s, researchers have started to model the mode choice by the structural equation modeling (SEM). SEM is a flexible linear-in-parameters multivariate statistical modeling technique [28]. Because it allows a set of relationships between one or more variables to be examined, it has been widely used in modeling travel behaviors and values [29]. Golob [28] did a complete review on SEM for travel behavior research. Ewing et al. [30] applied SEM to analyze the relationship between the mode of travel to school and the full range of factors that might affect this mode choice. It concluded that more students would likely choose walking or bike to commute under the following situations: (a) shorter travel time by walking or bike and (b) sidewalks on main roads to school. Li et al. [31] modeled a SEM to analyze factors influencing transit customers' loyalty in Shanghai. In addition, the SEM was also used for the analysis of travel demands [32] and the mode choice of urban residents [33].

From the above review of existing studies, SEM was identified as an efficient model for analyzing factors influencing the travel mode choice. Because the sample data are required to be positive-definite in the SEM, but factors related to the travel environment cannot always satisfy this requirement, this paper strives to combine the SEM with the comparative analysis to identify factors associated with travelers' characteristics and travel environment. By developing a SEM, the paper strives to identify significant factors of travelers' characteristics that influence the mode choice. Based on the results, the paper compares travel behaviors of residents with same characteristics in order to determine the influence of the traffic environment on the mode choice. In the end, the stated willingness and preconditions to shift the travel mode from cars to other alternative green modes are analyzed, which will help the government implement effective TDM policies for reducing short distance car trips in Beijing.

\section{Analysis of Factors Influencing Mode Choice}

3.1. Data Preparation. During the Fourth Comprehensive Traffic Survey in Beijing carried out in 2010 and 2011, the central city was divided into 902 traffic analysis zones (TAZs), in which 46.88 thousand households were surveyed, and 0.28 million of all sorts of trips from 0.11 million individuals were recorded. This research analyzed the distribution of short distance car trips as shown in Figure 1, which illustrates the number and the proportion of short distance car trips of interviewees of each TAZ in six districts of center Beijing.

In order to avoid bias of the proportion of short distance car trips caused by small sample size, both proportion and the number of short distance car trips should be taken into account. Based on the rule, the research selects three TAZs. The travel modes distribution of their short distance trips is shown in Figure 2. From this figure, it is clear that the proportions of short distance car trips of Zone 1 and Zone 2 are much higher than the average level in Beijing, and the proportions of short distance green-mode trips are much lower. On the contrary, the proportion of short distance car trips in Zone 3, 4.37\%, is much lower than the average level 


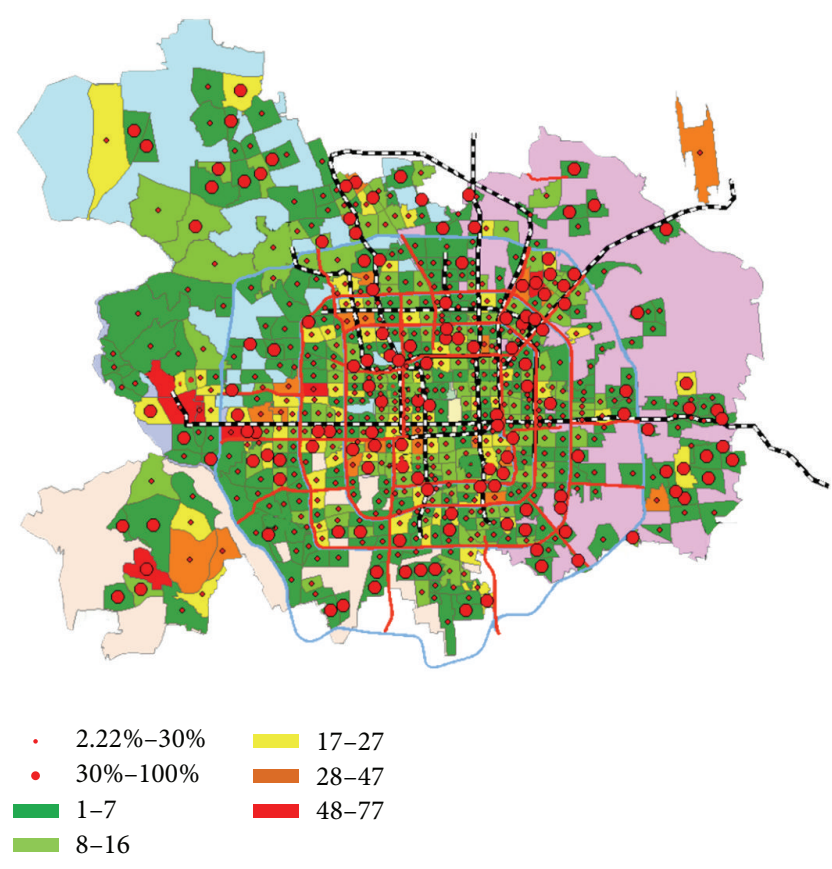

FIGURE 1: Number and proportion of short distance car trips in each TAZ.

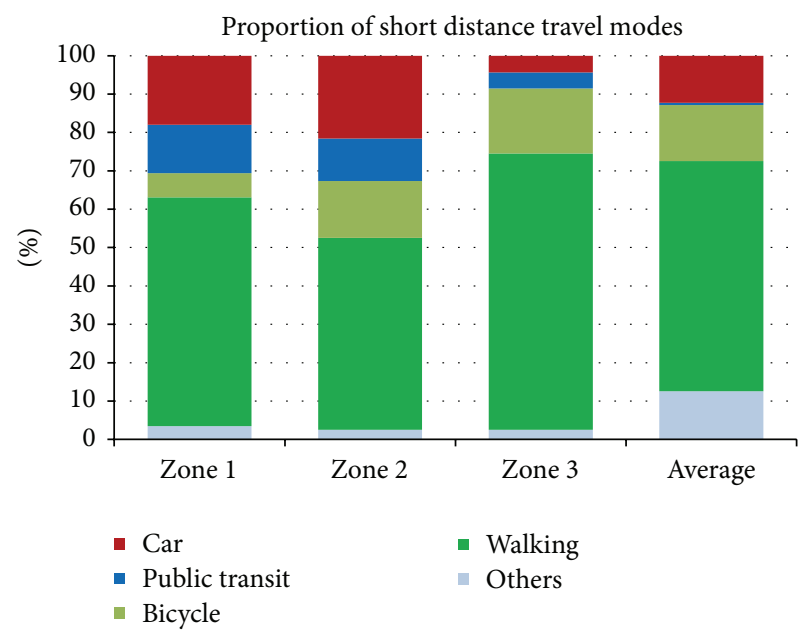

FIGURE 2: Proportion of short distance travel modes in three TAZs.

in Beijing. So, Zone 3 represents the kind of TAZ which has a good travel mode structure.

In order to combine the travel environment research with the residents' travel behaviors survey and to investigate the willingness and preconditions of mode shift, the research selected three typical residential areas according to the number of households in each zone. They are High Proportion Area 1A, High Proportion Area 1B, and Low Proportion Area 2, which were classified into two types. High Proportion Areas 1A and 1B represent residential areas with a high proportion of short distance car trips, while Low Proportion Area 2 represents the one with a low proportion. Furthermore, the study selected two groups of residents in each area. One is the group that mainly uses cars for short distance trips, and another one is the group that mainly uses green modes. Then, the study collected the data by a SP survey in order to analyze residents' travel behaviors and stated willingness to switch the mode. During the survey, this research improved the questionnaire quality by repetitious designs, field pretests, and modifications. In the end, the study collected 778 valid samples.

At the same time, the study surveyed the travel environment in each area and its extended region, which contains the area within 5 kilometers from the center of the area. The travel environment includes the vehicle travel environment and green-mode travel environment. For the vehicle travel environment, the paper selected several indexes, including the density of the internal vehicle road network, the density of the extended vehicle road network, and the average distance to nearby main roads. For the green-mode travel environment, the paper focused on the safety and convenience of green modes. Indexes include the width of walkway, the density of separated walkway and bus stops, and the distance to the nearest metro station. After the survey, results are summarized into Table 1. In High Proportion Areas 1A and $1 \mathrm{~B}$, the density of vehicle roads is higher and the distance to main roads is shorter than that in Low Proportion Area 2. However, the width of walkway, density of walkway, and bus stops are lower than those in Low Proportion Area 2. Thus, the vehicle travel environment in High Proportion Areas $1 \mathrm{~A}$ and $1 \mathrm{~B}$ is better than that in Low Proportion Area 2, but Low Proportion Area 2 has a better green-mode travel environment than the other two areas.

3.2. Traveler Characteristics Influencing Mode Choice. After collecting 778 valid questionnaires in three resident areas, the research did a statistical analysis on residents' mode choices in short distance trips. On the basis of existing findings $[30,33]$, this paper selected six common residents' characteristics, which influence residents' mode choices, including gender, age, household income, number of students, vehicle ownership, and bicycle ownership in the household [34]. In order to reduce the accidental error from the limited samples, the research only focused on car, bicycle, and walking and excluded some groups, like the group of age $(<20)$ for samples less than 50. It should be noted that the household income is a monthly income in the unit of thousand Chinese currency, RMB. Statistical results are shown in Figure 3.

As shown in Figure 3, there are different proportions of mode choices in short distance trips for residents with different characteristics, especially those with different household incomes or vehicle ownerships. For example, for the residents with the household income less than 5,500,34\% of this group is more likely to choose cars for short distance travels. With the increase of the income, the proportion of travels by cars increases as well.

In order to further identify the prior factors influencing the mode choice in short distance trips, the SEM model was selected in the research. Since the SEM is a confirmatory rather than an exploratory technique, the first step in applying SEM is the specification of a model. In order to meet the requirement of being positive-definite in SEM [28], 
TABLE 1: Comparison of travel environment in each area.

\begin{tabular}{|c|c|c|c|c|}
\hline & Index & $\begin{array}{c}\text { High } \\
\text { Proportion Area } \\
\text { 1A } \\
\end{array}$ & $\begin{array}{c}\text { High } \\
\text { Proportion Area } \\
1 \mathrm{~B} \\
\end{array}$ & $\begin{array}{l}\text { Low Proportion } \\
\quad \text { Area } 2\end{array}$ \\
\hline \multirow{3}{*}{$\begin{array}{l}\text { Vehicle travel } \\
\text { environment }\end{array}$} & $\begin{array}{l}\text { Density of internal vehicle road network } \\
\left(\mathrm{km} / \mathrm{km}^{2}\right)\end{array}$ & 11.7 & 14.3 & 9.3 \\
\hline & $\begin{array}{l}\text { Density of extended vehicle road network } \\
\left(\mathrm{km} / \mathrm{km}^{2}\right)\end{array}$ & 5.9 & 7.0 & 4.6 \\
\hline & Average distance to main roads around $(\mathrm{km})$ & 0.7 & 0.6 & 0.9 \\
\hline \multirow{5}{*}{$\begin{array}{l}\text { Green-mode travel } \\
\text { environment }\end{array}$} & Width of walkway $(\mathrm{m})$ & 1.9 & 2.8 & 4.0 \\
\hline & Density of separated walkway $\left(\mathrm{km} / \mathrm{km}^{2}\right)$ & 0.0 & 0.0 & 7.8 \\
\hline & $\begin{array}{l}\text { Density of bus stops around the area } \\
\left(\text { station } / \mathrm{km}^{2}\right)\end{array}$ & 18.2 & 7.0 & 44.4 \\
\hline & $\begin{array}{l}\text { Density of bus stops in extended region } \\
\left(\text { station } / \mathrm{km}^{2}\right)\end{array}$ & 7.9 & 6.7 & 8.7 \\
\hline & Distance to the nearest metro station $(\mathrm{km})$ & 4.8 & 2.3 & 1.4 \\
\hline
\end{tabular}

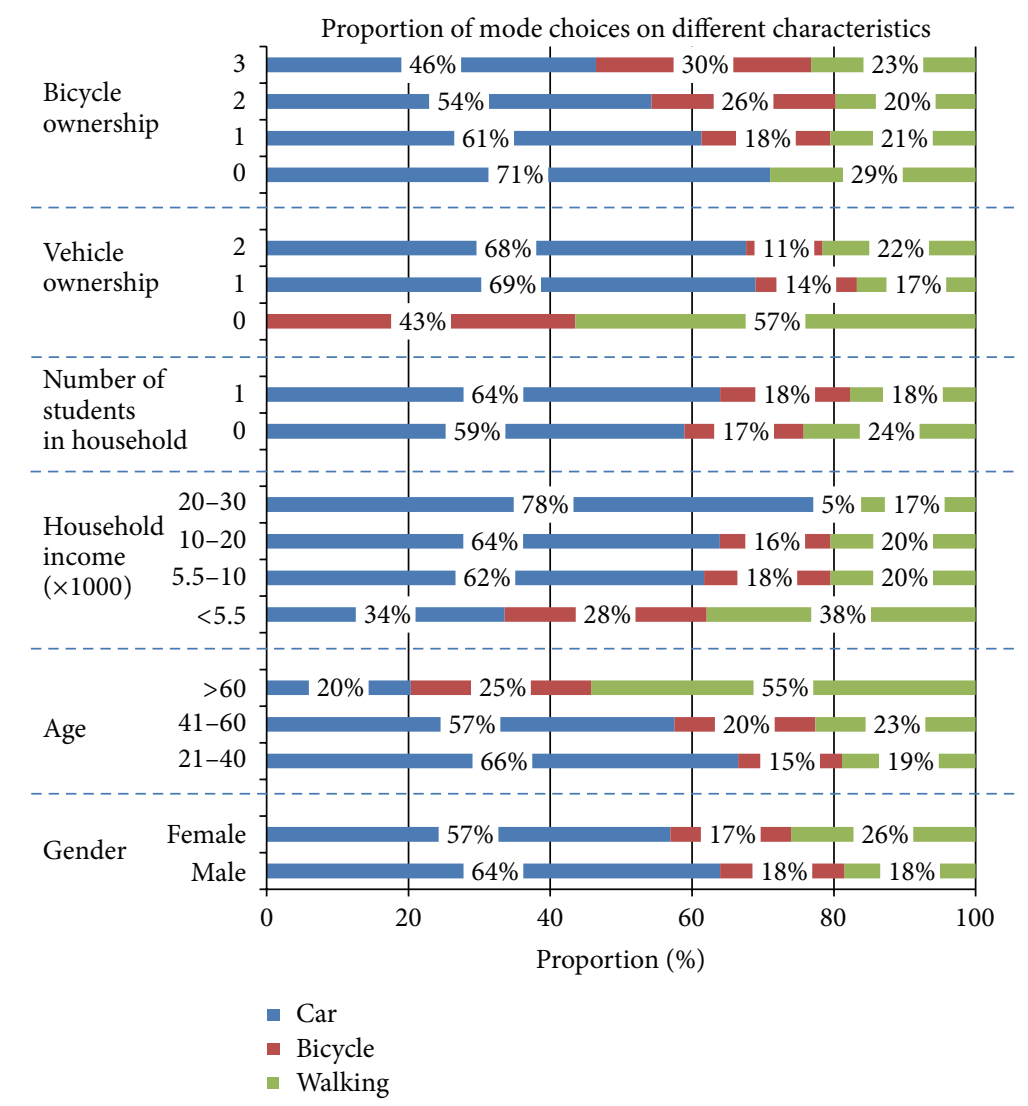

FIgURE 3: Proportion of mode choices in short distance trips.

the sample data that represent travelers' characteristics are organized and classified in SPSS as shown in Table 2. Then, the paper designs a primary SEM based on model variables as shown in Figure 4.

A number of criteria were developed for assessing the overall goodness-of-fit of the SEM and measuring how well one model does versus another one $[35,36]$. Until now, goodness-of-fit measures for a single model include indexes like the Root Mean Square Residual (RMSR), the Probability
Lever $(p)$, the Goodness-of-Fit Index (GFI), the Adjusted Goodness-of-Fit Index (AGFI), and the Root Mean Square Error of Approximation (RMSEA). In general, if the model could satisfy the conditions $p>0.05$, RMSEA $<0.08$, GFI $>$ 0.9 , and AGFI $>0.9$, the output of this model is considered acceptable [37].

In this paper, AMOS [36] is applied as a tool to solve the SEM model. In AMOS, the method most widely used for the estimation is the maximum likelihood (ML) estimation, 
TABLE 2: Descriptions of model variables.

\begin{tabular}{lll}
\hline Abbreviation & Characteristics & Description \\
\hline Gender & Gender & Male $=1 ;$ female $=2$ \\
Age & Age & $<20=1 ; 21-40=2 ; 41-60=3 ;>60=4$ \\
Income & $\begin{array}{l}\text { Household income } \\
(\times 1000 \mathrm{RMB})\end{array}$ & $<5.5=1 ; 5.5-10=2 ; 10-20=3 ; 20-30=4 ;>30=5$ \\
Student & Number of students in household & Numbers $0,1,2,3, \ldots \ldots$ \\
carHH & Vehicle ownership & Numbers $0,1,2,3, \ldots \ldots$ \\
bikeHH & Bicycle ownership & Numbers $0,1,2,3, \ldots \ldots$ \\
Mode & Travel mode & Car $=1 ;$ bicycle $=2 ;$ walking $=3$ \\
\hline
\end{tabular}

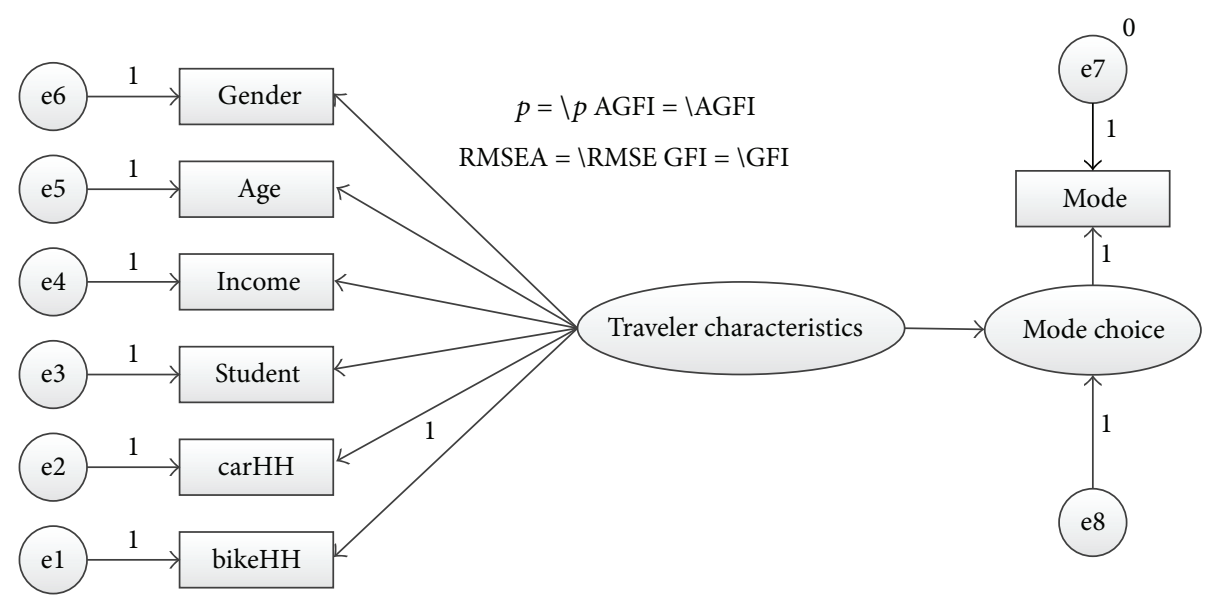

FIgURE 4: Primary structure of travelers' characteristics in the SEM.

which assumes multivariate normal data and a reasonable sample size. If the data are continuous but not normal, an alternative estimation method is asymptotically distribution free $(\mathrm{ADF}) . \mathrm{ADF}$ is good when the sample size is greater than 200 [38]. Because the SEM in this paper contains ordinal variables, and the sample size is 778 , the $\mathrm{ADF}$ is chosen for estimating parameters. After the model was estimated, evaluated, and modified in AMOS, several variables were eliminated since they had no significant effect on the mode choice, including "gender," "student," and "bikeHH." In the end, indexes for the model are $p=0.329$, RMSEA $=0.000$, GFI $=0.999$, and AGFI $=0.990$, which means that results of the SEM well satisfy the sample data. After the path analysis, results are shown in Figure 5.

Note. (1) C.R. is a ratio of the parameter estimate to the standard error, and $z$-statistics provide the statistical significance of the estimated parameter. (2) $X$ is a type of probability and the $* * *$ symbol indicates that the value is below 0.001 .

As shown in Figure 5, three of six factors, the age, household income, and vehicle ownership, have a significant effect on the mode choice. Standardized estimate represents the degree of effect between one factor and another. The effect of the vehicle ownership is bigger and its standardized estimate is -0.818 , and the standardized estimates of the age and household income are 0.391 and -0.556 . On the other hand, the effect of the household income is negative, but the effect of the age is positive, which means that, with the increase of the household income, the percentage of car trips will increase. With the increase of the age, the percentage of travels by the bicycle or walking will increase. It is noted that this conclusion may be different for developed countries. Because the trend of the urban traffic motorization has lasted for only 20 years in China, the senior citizens are still accustomed to travels by bicycles or walking. The above analysis implies that implementing TDM policies of reducing the car ownership may have a significant positive effect on reducing the short distance car trips.

3.3. Travel Environment Influencing Mode Choice. In order to explore the effect of the travel environment on the mode choice, the paper compared travelers with same residents' characteristics in all three areas. On the basis of the earlier analysis, the age, household income, and vehicle ownerships have a significant effect on the mode choice, so the same resident type is here defined as residents with the same age, household income, and vehicle ownerships. For the purpose of comparison, two samples were selected in the residents who mainly use cars for short distance trips, which had enough sample sizes.

It is observed from Figure 6 that the proportion of greenmode trips of Low Proportion Area 2 is significantly higher than that of High Proportion Areas 1A and 1B. In particular, in Sample 2, the proportions reached 39\% in Low Proportion Area 2, 18\% in High Proportion Area 1A, and 23\% in High 


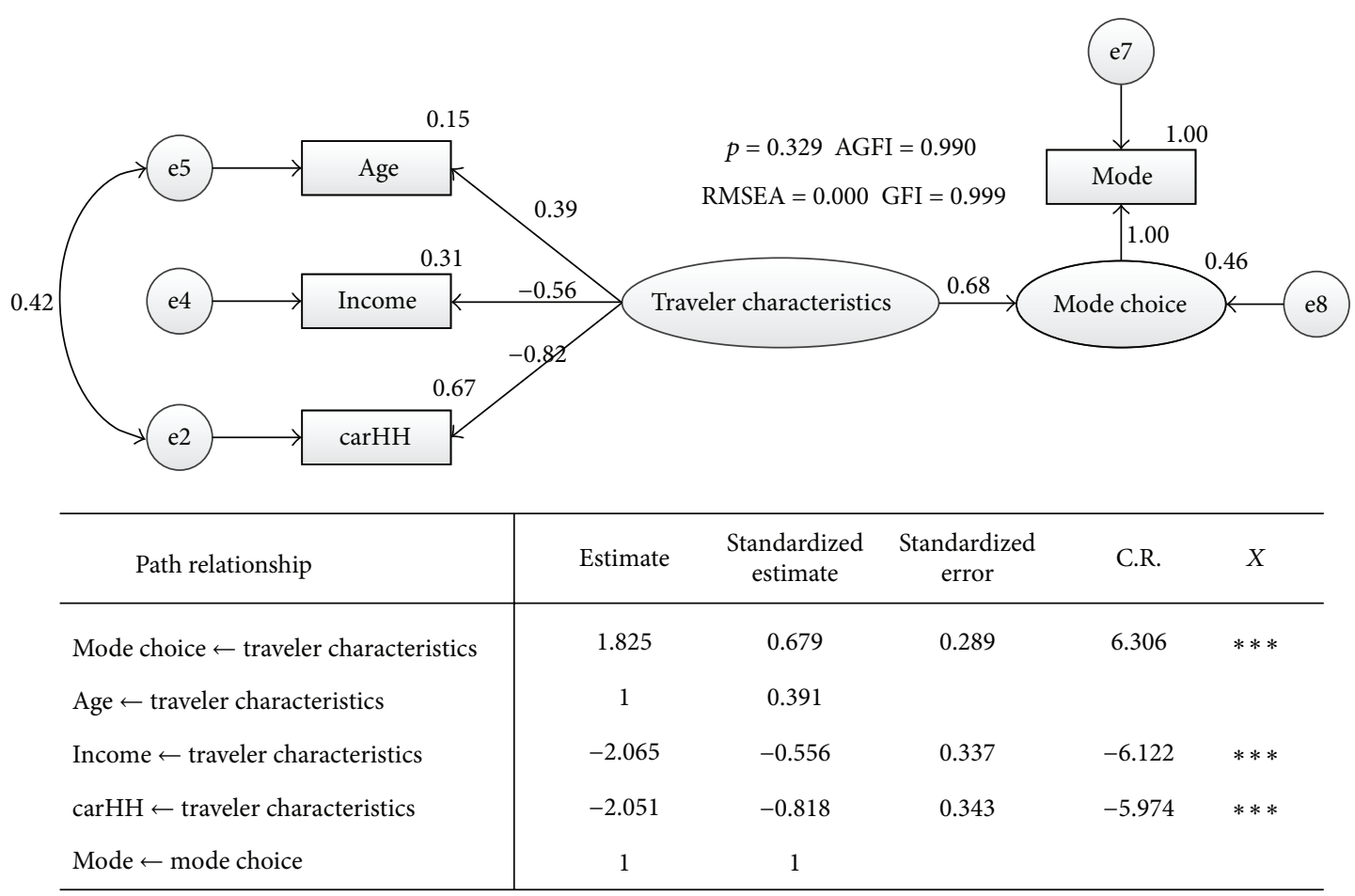

FIGURE 5: Effect of travelers' characteristics on mode choice.

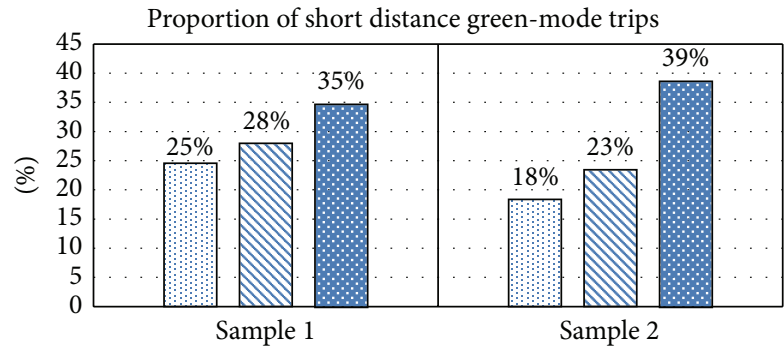

$\square$ High Proportion Area 1A
$\square$ Low Proportion Area 2
\ High Proportion Area 1B

FiguRE 6: Proportion of short distance green-mode trips.

Proportion Area 1B. As shown in Table 1, Low Proportion Area 2 has a better green-mode travel environment than the other two areas, so it can be observed that a better green-mode travel environment tends to result in a higher proportion of green-mode travels even for the same traveler group.

\section{Stated Willingness and Preconditions for Mode Shift}

Based on the earlier analysis, the paper discusses the stated willingness and preconditions for the mode shift from cars to the green mode for various travel purposes. The stated willingness is based on the 514 questionnaires on the residents who mainly use cars for short distance trips in High Proportion Areas 1A and 1B. Therefore, results are useful for the improvement of the travel environment. Besides, the mode shift preconditions include bike lane facilities, walkway facilities, and distance to bus stops. It should be explained that, for the bike lane and walkway, separated means that there is a physical separation between the motorway and the bike lane or walkway. Canopy is a facility covered on the walkway for protecting the pedestrian from rain and sunlight.

4.1. For Commuting. Due to nature of the subject short distance trips in this research, the bus and subway options are not considered. For the bicycle, it is observed that if the bicycle rental station is closer and the cycling path is wider, more residents will shift to the mode of bicycles for commuting. For the bicycle rental station, only $9.3 \%$ of respondents chose $500 \mathrm{~m}$ as their acceptable distance for the mode shift to the bicycle. On the other hand, $30.2 \%$ of residents chose the separated bike lane with more than $2.5 \mathrm{~m}$ width as their mode shift precondition. For the walkway facilities, $18.1 \%$ of residents will change their mode from cars to walking when the walkway is $3 \mathrm{~m}$ wide, separated, and covered with a canopy. Based on this, it is more effective to improve the travel environment for bicyclers.

4.2. For Picking-Up and Dropping-Off Children. The highest proportion of respondents who are willing to shift the mode for picking-up and dropping-off children is $27.4 \%$. It is lower than that for other three purposes $(30.2 \%, 51.9 \%$, and $39.7 \%)$. The reason may be the consideration of the safety of children, 
TABLE 3: Stated willingness of mode shift for various travel purposes.

\begin{tabular}{|c|c|c|c|c|c|}
\hline & Condition & For commuting & $\begin{array}{l}\text { For picking-up and } \\
\text { dropping-off children }\end{array}$ & For shopping & $\begin{array}{c}\text { For } \\
\text { visiting } \\
\text { friends } \\
\end{array}$ \\
\hline \multirow{3}{*}{$\begin{array}{l}\text { Distance to } \\
\text { bicycle rental } \\
\text { station }\end{array}$} & In $1500 \mathrm{~m}$ & $2.1 \%$ & $0.4 \%$ & $0.2 \%$ & $0.2 \%$ \\
\hline & In $1000 \mathrm{~m}$ & $3.9 \%$ & $1.6 \%$ & $1.4 \%$ & $0.4 \%$ \\
\hline & In $500 \mathrm{~m}$ & $9.3 \%$ & $4.1 \%$ & $6.2 \%$ & $3.7 \%$ \\
\hline \multirow{3}{*}{$\begin{array}{l}\text { Bike lane } \\
\text { facilities }\end{array}$} & $1.5 \mathrm{~m}$ (width), ride with traffic & $1.8 \%$ & $0.8 \%$ & $0.6 \%$ & $0.2 \%$ \\
\hline & $2.5 \mathrm{~m}$, separated & $6.2 \%$ & $5.3 \%$ & $5.8 \%$ & $1.0 \%$ \\
\hline & $>2.5 \mathrm{~m}$, separated & $30.2 \%$ & $13.8 \%$ & $19.1 \%$ & $8.8 \%$ \\
\hline \multirow{4}{*}{$\begin{array}{l}\text { Walkway } \\
\text { facilities }\end{array}$} & $1.5 \mathrm{~m}$, ride with traffic, no canopy & $1.0 \%$ & $0.2 \%$ & $0.0 \%$ & $0.2 \%$ \\
\hline & $1.5 \mathrm{~m}$, separated, no canopy & $2.9 \%$ & $1.4 \%$ & $1.8 \%$ & $1.6 \%$ \\
\hline & $1.5 \mathrm{~m}$, ride with traffic, with canopy & $1.6 \%$ & $0.6 \%$ & $2.7 \%$ & $1.6 \%$ \\
\hline & $3 \mathrm{~m}$, separated, with canopy & $18.1 \%$ & $10.9 \%$ & $14.8 \%$ & $9.5 \%$ \\
\hline \multirow{4}{*}{$\begin{array}{l}\text { Distance to } \\
\text { bus stops }\end{array}$} & In $1000 \mathrm{~m}$ & - & $1.0 \%$ & - & $0.0 \%$ \\
\hline & In $800 \mathrm{~m}$ & - & $2.5 \%$ & - & $2.3 \%$ \\
\hline & In $500 \mathrm{~m}$ & - & $11.5 \%$ & - & $20.0 \%$ \\
\hline & In $300 \mathrm{~m}$ & - & $27.4 \%$ & - & $39.7 \%$ \\
\hline \multirow{4}{*}{$\begin{array}{l}\text { Travel time } \\
\text { by bus }\end{array}$} & 3 times that by car & - & $0.0 \%$ & - & $0.2 \%$ \\
\hline & 2 times that by car & - & $9.1 \%$ & - & $11.5 \%$ \\
\hline & Equal to that by car & - & $24.7 \%$ & - & $28.8 \%$ \\
\hline & Less than that by car & - & $27.0 \%$ & - & $30.9 \%$ \\
\hline \multirow{4}{*}{$\begin{array}{l}\text { Distance to } \\
\text { subway } \\
\text { station }\end{array}$} & In $1500 \mathrm{~m}$ & - & $0.4 \%$ & - & - \\
\hline & In $1000 \mathrm{~m}$ & - & $1.0 \%$ & - & - \\
\hline & In $800 \mathrm{~m}$ & - & $8.2 \%$ & - & - \\
\hline & In $500 \mathrm{~m}$ & - & $19.6 \%$ & - & - \\
\hline \multirow{3}{*}{ School bus } & Travel time less than $10 \mathrm{~min}$ & - & $14.2 \%$ & - & - \\
\hline & Travel time less than $20 \mathrm{~min}$ & - & $0.8 \%$ & - & - \\
\hline & No accident in recent 2 years & - & $18.3 \%$ & - & - \\
\hline \multirow{4}{*}{$\begin{array}{l}\text { Distance to } \\
\text { shuttle }\end{array}$} & In $1000 \mathrm{~m}$ & - & - & $0.4 \%$ & - \\
\hline & In $800 \mathrm{~m}$ & - & - & $1.8 \%$ & - \\
\hline & In $500 \mathrm{~m}$ & - & - & $19.8 \%$ & - \\
\hline & In $300 \mathrm{~m}$ & - & - & $51.9 \%$ & - \\
\hline \multirow{4}{*}{$\begin{array}{l}\text { Travel time } \\
\text { by shuttle }\end{array}$} & 3 times that by car & - & - & $0.8 \%$ & - \\
\hline & 2 times that by car & - & - & $13.2 \%$ & - \\
\hline & Equal to that by car & - & - & $39.3 \%$ & - \\
\hline & Less than that by car & - & - & $41.6 \%$ & - \\
\hline
\end{tabular}

which makes some parents unwilling to give up cars. In spite of this, $27.4 \%$ of respondents chose $300 \mathrm{~m}$ as the acceptable distance between the bus stop and the trip origin. In terms of the travel time by the bus, if it is equal to the travel time by cars, $24.7 \%$ of respondents will shift from the car mode to the bus. This may relate to the limitation of parking spaces for cars in Beijing. If the travel time by the bus is double the travel time by the car, the proportion decreased to $9.1 \%$. However, when the travel time by the bus is triple the travel time by cars, no respondent is willing to choose the bus. Considering the findings above, it is meaningful to develop more bus lanes to shorten the travel time by the bus, which could attract some residents to shift from the car mode to the bus. On the other hand, there are $14.2 \%$ of respondents who are willing to change into the school bus if the travel time is less than $10 \mathrm{~min}$, while $18.3 \%$ of respondents will change if the school bus has no accident in recent 2 years.

4.3. For Shopping. For the purpose of shopping, there is a higher demand on shopping shuttles while there is a lower willingness of choosing walking or bicycle. More than $50 \%$ of respondents chose the shopping shuttle if the required travel environment is met, but less than $20 \%$ chose the bicycle or walking. The reason may be that there are no time limitations for shopping using the shuttle, and the shuttle is free and convenient. From Table 3, 51.9\% of respondents chose $300 \mathrm{~m}$ as the acceptable distance between the shuttle stop and the trip origin, while $19.8 \%$ chose $500 \mathrm{~m}$. If the distance is longer, 
the proportion is less than $2 \%$. For the travel time, if it is less than that by cars, $41.6 \%$ will change from cars to the shopping shuttle.

4.4. For Visiting Friends. For the purpose of visiting friends, less than $10 \%$ of respondents chose walking or bicycle no matter how much the environment is improved. But if the distance from the origin to the bus stops is within $300 \mathrm{~m}$, the proportion of respondents who chose the bus is $39.7 \%$. When the distance is within $500 \mathrm{~m}$, the proportion decreased to $20.0 \%$. In terms of the travel time by the bus, if the time is equal to the travel time by cars, $28.8 \%$ of respondents will give up cars. If the time is double the travel time by cars, the proportion decreased to $11.5 \%$. Further, almost none of them will use the bus when the travel time by the bus is triple the travel time by cars.

\section{Conclusions and Recommendations}

In order to reduce the percentage of short distance car trips, this paper attempted to identify prior factors of travelers' characteristics and the travel environment that influence the mode choice in Beijing. Main findings of this paper can be summarized as follows.

(1) Three travelers' characteristics, the age, household income, and vehicle ownerships, have a significant effect on the mode choice in short distance trips. The effect of the vehicle ownerships is bigger than other factors and its standardized estimate is -0.818 , and standardized estimates of the age and household income are 0.391 and -0.556 .

(2) A better green-mode travel environment leads to a higher proportion of green-mode travels. Facilities and the environment of the green travel mode in Low Proportion Area 2 are better than those in High Proportion Areas $1 \mathrm{~A}$ and 1B, so the same type of residents in Low Proportion Area 2 shows a significant higher proportion of green-mode travelers than those in other areas.

(3) Overall, respondents are more willing to choose the cycling if the bicycle path is wider and the rental station is closer. If the mode shift precondition is met, for the trip purpose of commuting, 30.2\% of the residents who mainly use cars for short distance trips in High Proportion Areas $1 \mathrm{~A}$ and $1 \mathrm{~B}$ are willing to shift to the cycling. For the purpose of pickingup and dropping-off children, $18.3 \%$ of respondents are willing to choose the school bus if the bus has no accident records in recent 2 years. For the purpose of shopping, as high as $51.9 \%$ of respondents are willing to choose the shopping shuttle if the distance from the trip origin to the shuttle stops is within $300 \mathrm{~m}$. For the purpose of visiting friends, if the distance from the origin to the bus stops is within $300 \mathrm{~m}$, the mode shift proportion is $39.7 \%$.

The above findings will help identify which of the alternative travel modes are likely to be attractive to car travelers in order to maximize the potential reductions in car uses in short distance trips. Further studies are recommended in two aspects. First, by considering that it is a possibility the area leads people who want to behave differently to choose the area for their residence (self-selection problem), an indepth research should focus on the self-selection problem and study its effect on mode choice. Second, more residential areas should be selected for comparing the difference of the environment and the travel behavior. In addition, in order to reveal a more realistic preference instead of the willingness which people would like to state; more sophisticated stated preference analysis methods should be investigated.

\section{Conflict of Interests}

The authors declare that there is no conflict of interests regarding the publication of this paper.

\section{Acknowledgments}

This research is supported in part by the National Basic Research Program of China no. 2012CB725403, the Natural Science Foundation of China (NSFC) nos. 71273024 and 51208033, the National Science Foundation (NSF) Grant no. 1137732, and the Fundamental Research Funds no. T14JB00180. The authors would be thankful to all the personnel who either provided the technical supports or helped on data collection and processing.

\section{References}

[1] Beijing Transportation Research Center, Beijing Transport Annual Report 2011, Beijing Transportation Research Center, 2011.

[2] Beijing Transportation Research Center, The Fourth Comprehensive Traffic Survey in Beijing (Draft), Beijing Transportation Research Center, 2012.

[3] Beijing Jiaotong University, Study on Short Distance Car Trips in Beijing-Opportunities for Emission Reduction, Beijing Jiaotong University, Beijing, China, 2012.

[4] S. Algers, "Integrated structure of long-distance travel behavior models in Sweden," Transportation Research Record: Journal of the Transportation Research Board, no. 1413, pp. 141-149, 1993.

[5] W. J. Mallett, "Long-distance travel by low-income households," Transportation Research Board, vol. E-C026, pp. 169-177, 2001.

[6] W. J. Mallett, "Long-distance travel by women: results from the 1995 American travel survey," Transportation Research Record: Journal of the Transportation Research Board, no. 1693, pp. 71$78,1999$.

[7] N. Limtanakool, M. Dijst, and T. Schwanen, "The influence of socioeconomic characteristics, land use and travel time considerations on mode choice for medium- and longer-distance trips," Journal of Transport Geography, vol. 14, no. 5, pp. 327-341, 2006.

[8] N. Limtanakool, M. Dijst, and T. Schwanen, "On the participation in medium- and long-distance travel: a decomposition analysis for the UK and the Netherlands," Tijdschrift voor Economische en Sociale Geografie, vol. 97, no. 4, pp. 389-404, 2006. 
[9] R. L. Mackett, "Why do people use their cars for short trips?" Transportation, vol. 30, no. 3, pp. 329-349, 2003.

[10] R. L. Mackett, "Policies to attract drivers out of their cars for short trips," Transport Policy, vol. 8, no. 4, pp. 295-306, 2001.

[11] A. de Nazelle, B. J. Morton, M. Jerrett, and D. CrawfordBrown, "Short trips: an opportunity for reducing mobile-source emissions?" Transportation Research, Part D: Transport and Environment, vol. 15, no. 8, pp. 451-457, 2010.

[12] E. Maibach, L. Steg, and J. Anable, "Promoting physical activity and reducing climate change: opportunities to replace short car trips with active transportation," Preventive Medicine, vol. 49, no. 4, pp. 326-327, 2009.

[13] S. Forward, "Modes of transport of short journeys: attitudes and behavior of the inhabitants of Gothenburg," VTI Rapport, vol. 437, 1998.

[14] T. Y. Wu and X. Li, "Research on rapid development of short distance travel in China," Technology for Education and Learning, vol. 136, pp. 495-502, 2012.

[15] M. Kuby, A. Barranda, and C. Upchurch, "Factors influencing light-rail station boardings in the United States," Transportation Research Part A: Policy and Practice, vol. 38, no. 3, pp. 223-247, 2004.

[16] B. P. Y. Loo, C. Chen, and E. T. H. Chan, "Rail-based transitoriented development: lessons from New York City and Hong Kong," Landscape and Urban Planning, vol. 97, no. 3, pp. 202212, 2010.

[17] D. Walton and S. Sunseri, "Factors influencing the decision to drive or walk short distances to public transport facilities," International Journal of Sustainable Transportation, vol. 4, no. 4, pp. 212-226, 2010.

[18] S. Kim and G. F. Ulfarsson, "Curbing automobile use for sustainable transportation: analysis of mode choice on short home-based trips," Transportation, vol. 35, no. 6, pp. 723-737, 2008.

[19] R. Cervero and K. Kockelman, "Travel demand and the 3Ds: density, diversity, and design," Transportation Research, Part D: Transport and Environment, vol. 2, no. 3, pp. 199-219, 1997.

[20] S. Handy, X. Cao, and P. Mokhtarian, "Correlation or causality between the built environment and travel behavior? Evidence from Northern California," Transportation Research Part D: Transport and Environment, vol. 10, no. 6, pp. 427-444, 2005.

[21] R. Crane and R. Crepeau, "Does neighborhood design influence travel?: a behavioral analysis of travel diary and GIS data," Transportation Research Part D: Transport and Environment, vol. 3, no. 4, pp. 225-238, 1998.

[22] M. Ben-Akiva, A. de Palma, and P. Kanaroglou, "Dynamic model of peak period traffic congestion with elastic arrival rates," Transportation Science, vol. 20, no. 3, pp. 164-181, 1986.

[23] Central Transportation Planning, Transfer Penalties in Urban Mode Choice Modeling, U.S. Department of Transportation, Washington, DC, USA, 1997.

[24] O. Ivanova, "A note on the consistent aggregation of nested logit demand functions," Transportation Research Part B: Methodological, vol. 39, no. 10, pp. 890-895, 2005.

[25] S. Jones and D. A. Hensher, "Modelling corporate failure: a multinomial nested logit analysis for unordered outcomes," The British Accounting Review, vol. 39, no. 1, pp. 89-107, 2007.

[26] J. S. Chipman, “The foundations of utility," Econometrica, vol. 28, no. 2, pp. 193-224, 1960.

[27] C. R. Bhat, "A heteroscedastic extreme value model of intercity travel mode choice," Transportation Research Part B: Methodological, vol. 29, no. 6, pp. 471-483, 1995.
[28] T. F. Golob, "Structural equation modeling for travel behavior research," Transportation Research Part B: Methodological, vol. 37, no. 1, pp. 1-25, 2003.

[29] R. B. Kline, "Software programs for structural equation modeling: Amos, EQS, and LISREL," Journal of Psychoeducational Assessment, vol. 16, no. 4, pp. 343-364, 1998.

[30] R. Ewing, W. Schroeer, and W. Greene, "School location and student travel analysis of factors affecting mode choice," Journal of the Transportation Research Board, vol. 1895, pp. 55-63, 2004.

[31] L. B. Li, J. Xiong, Z. Dong, Y. Bai, and B. Wu, Exploring Factors Affecting Transit Current Customers' Loyalty by Structural Equations Model: Case Study of Shanghai, China, Transportation Research Board, Washington, DC, USA, 2013.

[32] Q. Zhou, Y. Li, C. Meng, and H. Lu, "Analysis of travel demand based on a structural equation model," Journal of Tsinghua University: Science \& Technology, vol. 48, no. 5, pp. 879-882, 2008.

[33] L. Y. Yang, C. F. Shao, and X. Li, "Structural equation model analysis of travel mode choice for urban residents," Journal of Beijing Jiaotong University, vol. 35, no. 6, pp. 1-6, 2011.

[34] Department of Transport, National Travel Survey: 2011, Department of Transport, London, UK, 2012.

[35] P. M. Bentler, "Comparative fit indexes in structural models," Psychological Bulletin, vol. 107, no. 2, pp. 238-246, 1990.

[36] L.-T. Hu and P. M. Bentler, "Cutoff criteria for fit indexes in covariance structure analysis: conventional criteria versus new alternatives," Structural Equation Modeling, vol. 6, no. 1, pp. 1$55,1999$.

[37] M. L. Wu, Structural Equation Model: Operation and Application, Chongqing University Press, Chongqing, China, 2010.

[38] K. G. Jöreskog and D. Sörbom, PRELIS: A Program for Multivariate Data Screening and Data Summarization-A Preprocessor for LISREL, Scientific Software, Mooresville, NC, USA, 1988. 


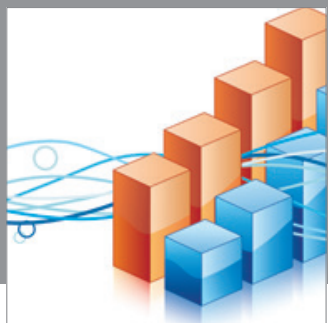

Advances in

Operations Research

mansans

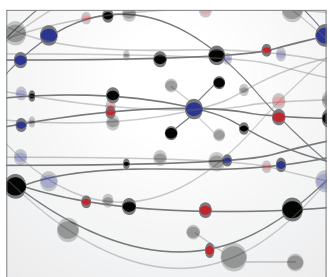

The Scientific World Journal
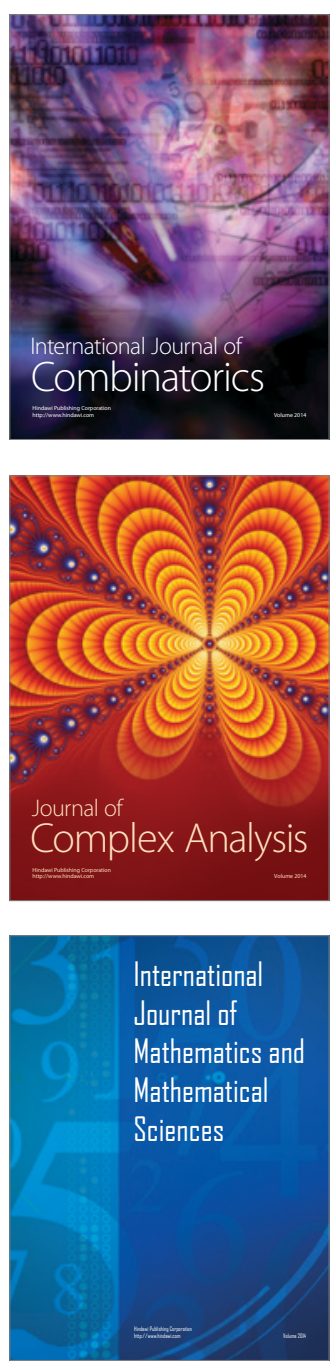
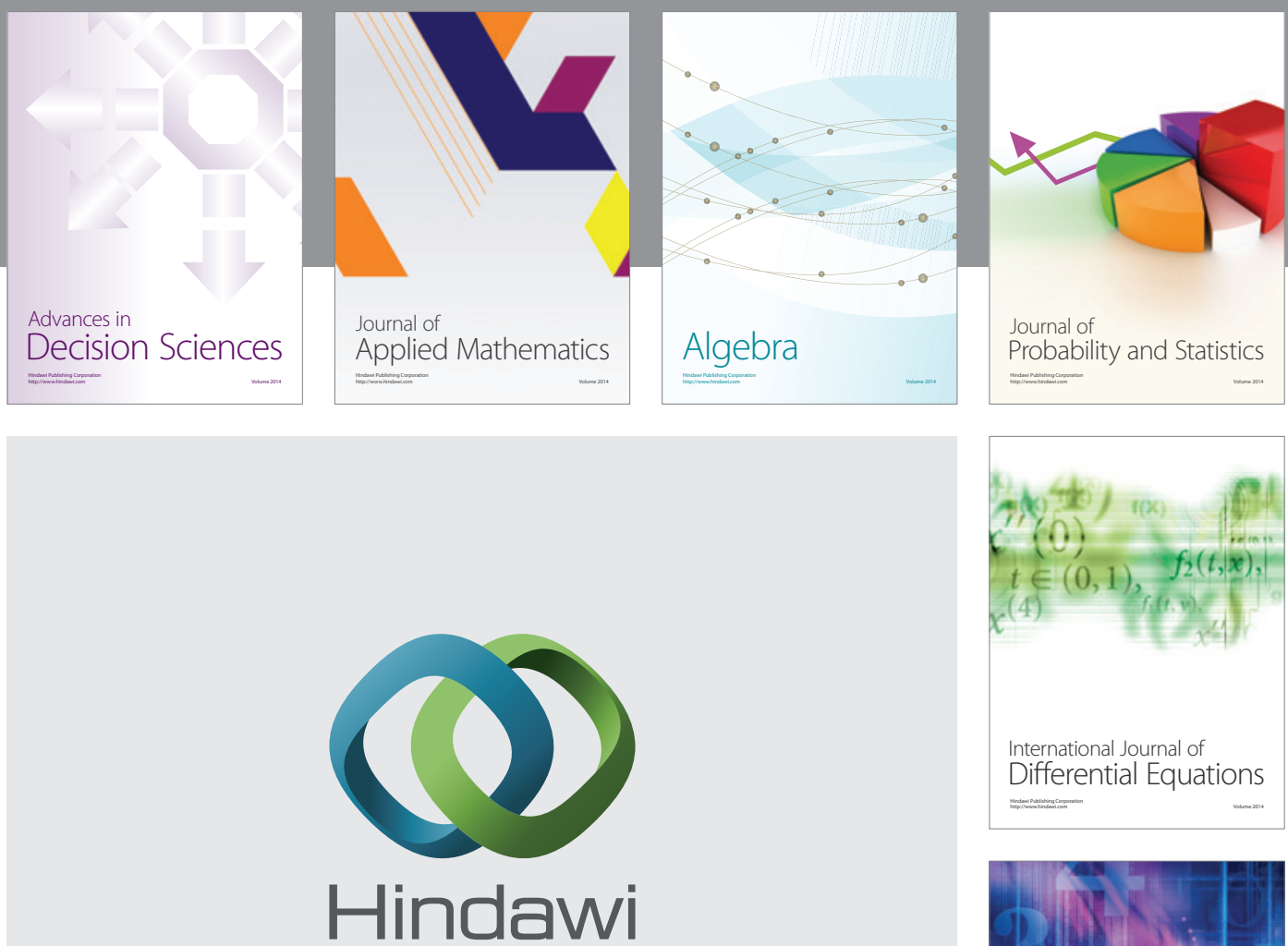

Submit your manuscripts at http://www.hindawi.com
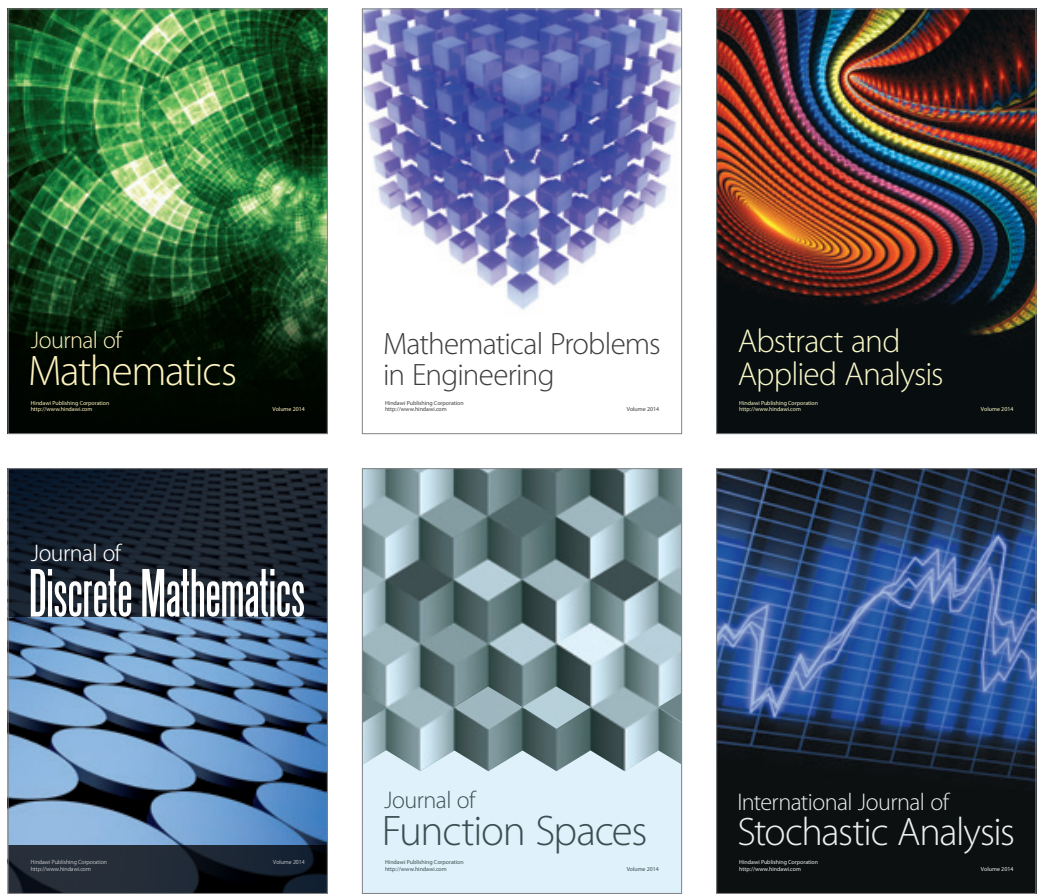

Journal of

Function Spaces

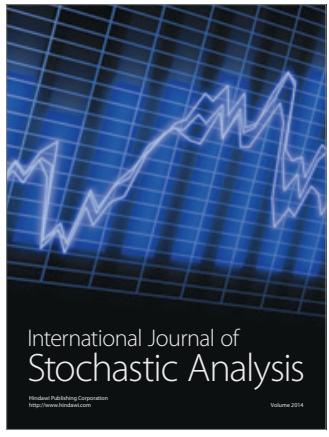

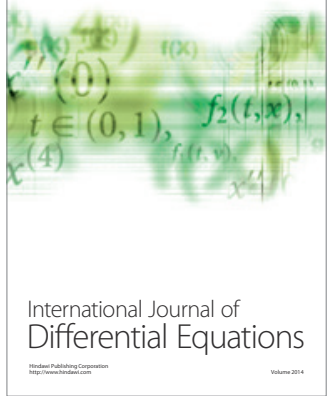
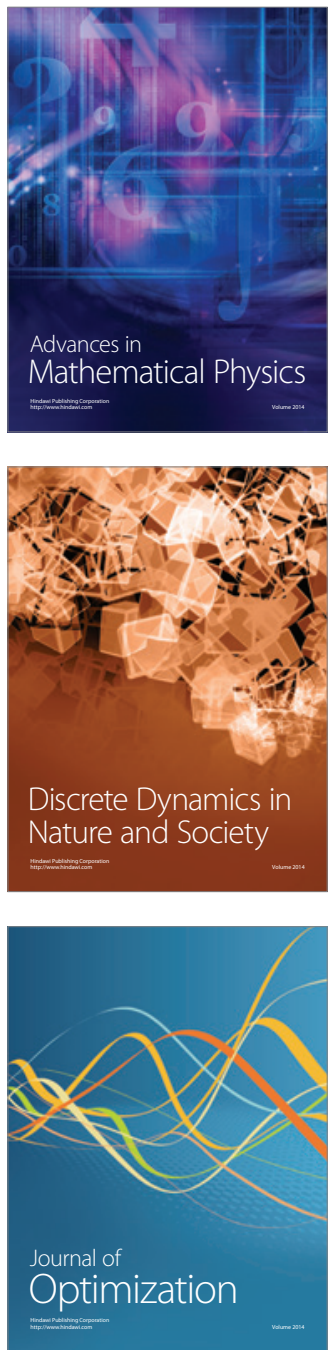